\section{Sensitivity of self-potentiating effect of luteinising hor mone-releasing hormone to cycloheximide}

THE hypophysiotropic luteinising h ormone--releasing hormone (LHRH) has a number of distinct actions on the anterior pituitary gland. In addition to stimulating the release and increased synthesis of gonadotrophins ${ }^{1}$, this peptide also has a priming or self-potentiating effect so that intermittent stimulation of the pituitary with identical doses of LHRH causes a progressively increasing series of responses of luteinisinghormone (LH) secretion. Self-potentiation by LHRH has been observed in vivo in rats ${ }^{2}$ and $\operatorname{man}^{3}$ and may play an important role in the generation of the $\mathrm{LH}$ surge which precedes ovulation. The effect can be obtained ${ }^{4}$ following repeated, brief exposures of the isolated, perifused rat pituitary gland to LHRH and the time course of development and decay of the potentiated state in these conditions is similar to that observed in the intact rat $^{2}$. We have investigated the effects of an inhibitor of protein synthesis on this phenomenon and report here that cycloheximide suppresses the priming effect of LHRH without impairing the acute response of LH release.

Pituitary glands from four dioestrous female rats were halved and divided into two groups of paired halves. Each group was placed in an identical Millipore Swinnex filter chamber and perifused simultaneously at $37^{\circ} \mathrm{C}$ with Krebs-Ringer bicarbonate medium ( $p \mathrm{H}$ 7.4) containing bovine serum albumin $\left(2.5 \mathrm{~g} \mathrm{l}^{-1}\right)$, glucose $\left(2 \mathrm{~g} \mathrm{l}^{-1}\right)$ and gassed with $95 \% \mathrm{O}_{2}-5 \% \mathrm{CO}_{2}$ $(\mathrm{v} / \mathrm{v})$. The flow rate was maintained at $0.2 \mathrm{ml} \mathrm{min}^{-1}$ by means of a peristaltic pump and the effluent medium was collected every $10 \mathrm{~min}$ ( $2 \mathrm{ml}$ fractions) and assayed for LH using an $\mathrm{NIH}$ radioimmunoassay kit.

Cycloheximide $(5 \mu \mathrm{M})$ was added to the medium used to perifuse one group of halved pituitaries whereas the other group received only the control medium. After an initial period of $100 \mathrm{~min}$ in which the secretion of $\mathrm{LH}$ was allowed to decline towards basal levels, both groups of halved glands were subjected to 5 mins perifusion with $10 \mathrm{ng}$ of synthetic LHRH dissolved in $1 \mathrm{ml}$ of perifusion medium, introduced by transferring the inlet tube of the system to the test sample. Identical challenges with LHRH were administered at intervals of $1 \mathrm{~h}$ for a further period of $4 \mathrm{~h}$ and the effects on $\mathrm{LH}$ secretion in both groups are shown in Fig. 1.

Control and cycloheximide treated groups both showed similar patterns of LH secretion during the preliminary period of perifusion and also in response to the first stimulation with LHRH, which was given before LH secretion had reached basal levels. With subsequent exposures to LHRH, however, only the hemipituitaries perifused with control medium showed the typical pattern of increasing responsiveness to LHRH and after five such challenges the rate of secretion of $\mathrm{LH}$ had risen to about five times that of the glands treated with cycloheximide. The latter did not exhibit a potentiated response and a series of equal peaks of $\mathrm{LH}$ secretion were obtained in the presence of $5 \mu \mathrm{M}$ cycloheximide.

Inhibition of the self-potentiating effect of LHRH has been consistently obtained in similar experiments in which concentrations of cycloheximide ranging from $5 \mu \mathrm{M}$ to $250 \mu \mathrm{M}$ were used. In no case was the acute release of $\mathrm{LH}$ in response to LHRH abolished. Dissociation between the acute release of $\mathrm{LH}$ and the development of enhanced responsiveness to a series of LH-releasing stimuli has also been obtained in preliminary experiments in which isolated perifused pituitary glands were exposed for $5 \mathrm{~min}$ to medium containing $50 \mathrm{mM} \mathrm{K}^{+}$. Osmolarity was maintained by adjusting the $\mathrm{Na}^{+}$concentration and the stimulus was administered at 1-h intervals. The high potassium medium caused an acute release of $\mathrm{LH}$ similar to that observed with LHRH but, as in the presence of cycloheximide,

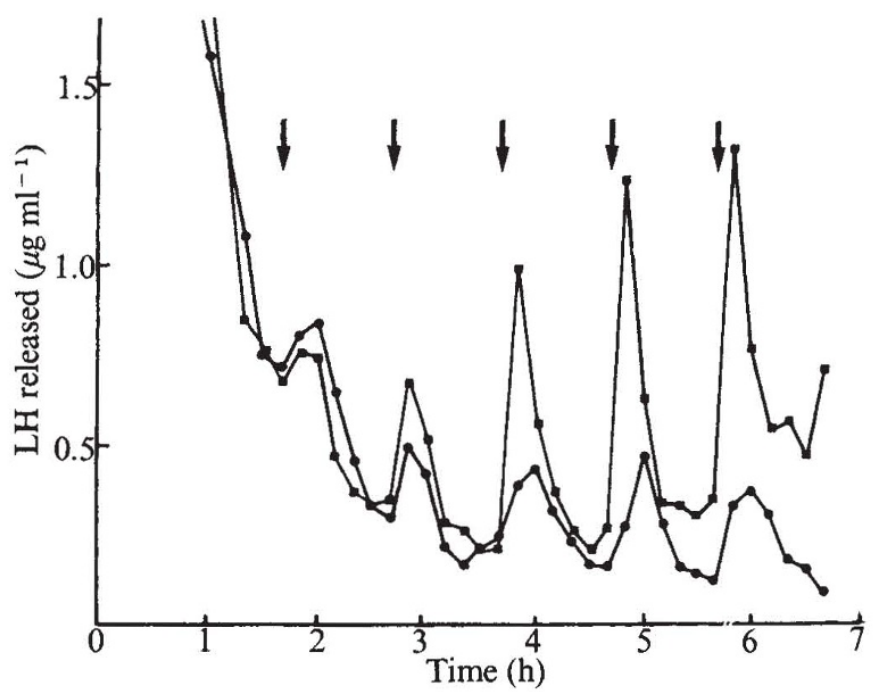

Fig. 1 Effect of cycloheximide on stimulation of $\mathrm{LH}$ release by LHRH. Two groups of paired, halved rat adenohypophyses were simultaneously perfused with Krebs-Ringer bicarbonate medium alone ( $\square$ ) and containing $5 \mu \mathrm{M}$ cycloheximide $(0)$. Glands were exposed to synthetic LHRH $\left(10 \mathrm{ng} \mathrm{ml}^{-1}\right)$ for $5 \mathrm{~min}$ at the times indicated by arrows. LH released to the perifusion medium in $10 \mathrm{~min}$ intervals was measured by radioimmunoassay and results are expressed in terms of the NIAMD-rat LH-RP-1 reference preparation. Cycloheximide abolished the self-potentiation produced by LHRH without reducing the acute release of $\mathrm{LH}$.

the series of $\mathrm{LH}$ peaks were of equal magnitude and did not exhibit the increased responsiveness shown by glands primed with LHRH.

These results show clearly that the augmented release of $\mathrm{LH}$ which occurs from the primed pituitary gland represents a specific response to the hypophysiotropic hormone rather than a nonspecific sequel to the discharge of LH. Release of $\mathrm{LH}$ evoked by LHRH in the presence of cycloheximide or induced by depolarising levels of $\mathrm{K}^{+}$does not cause a potentiated response to further stimulation. The priming effect would seem to involve the synthesis of new proteins and it has been suggested that increased synthesis of LH may be important ${ }^{3}$. Only a small percentage of the $\mathrm{LH}$ content of the gland is, however, released in response to acute stimulation with a supramaximal dose of LHRH. An intermittent exposure to LHRH in the presence of cycloheximide does not cause a diminution of the acute secretory response. It is likely that the availability of $\mathrm{LH}$ is not a limiting factor and that the synthesis of some other component of the release mechanism may be essential for self-potentiation to occur. The effects of LHRH and cycloheximide on the incorporation of labelled amino acids into $\mathrm{LH}$ and various subcellular components are being studied and should resolve this issue.

This work was partly supported by an MRC programme grant. We thank C. O'Neil and Mrs J. Pennington for technical assistance. Rat LH immunoassay materials were provided by the NIAMD-NIH rat hormone distribution programme and the LHRH was donated by Roche Products Ltd.

\section{J. A. EDWARDSON}

Department of Biochemistry,

Imperial College,

London $S W 72 A Z, U K$

\section{Gilbert}

Department of Biophysics and Biochemistry,

Wellcome Research Laboratories, Beckenham, BR3 3BS, UK

Received February 20; accepted March 10, 1975.

1 Schally, A. V., et al., Science, 173, 1036 (1971).

Aiyer, M. S., Chiappa, S. A., and Fink, G., J. Endocr., 62, 573-588 (1974).

(Kh), 184, 21 (1974).

Gilbert, D., and Edwardson, J. A., J. Endocr., 63, 23P (1974). 